\title{
Tópicos de Linguística e Literatura no Letramento e na Formação de Alfabetizadores
}

\author{
Eliabe Bezerra de Oliveira Silva ${ }^{l}$
}

\begin{abstract}
Resumo: O presente artigo tem como título "Tópicos de Linguística e Literatura no letramento e na formação de alfabetizadores" e trata de conhecimentos da Linguística e da Literatura que precisam de ressignificação na formação acadêmica inicial e contínua de professores alfabetizadores. O intuito deste trabalho não é dissertar a respeito de teorias e correntes da Linguística acerca do letramento inicial ou discorrer sobre fonologia da língua portuguesa, nem argumentar sobre Teoria, Crítica ou História da Literatura, mas é provocar reflexão e discussão a respeito de tópicos do arcabouço teórico da Linguística e da Literatura ausentes ou mal compreendidos na formação de pedagogos alfabetizadores e professores de Língua Portuguesa. Dentro dessa proposta, é imperativo fazer considerações breves também sobre mudanças paradigmáticas na formação de professores e sobre a implicação dos problemas analisados no percurso escolar dos estudantes. Sob o método da pesquisa bibliográfica, com cruzamento de fontes dos últimos dez anos e outras mais antigas, e interpretação de conteúdo, os argumentos foram construídos no sentido de retomar a importância do tema paralelamente a outros predominantes nos discursos acadêmicos. Araújo e Oliveira (2008) e Pimenta (1996), dentre outros, formam as referências de embasamento teórico e contribuem para o resultado da pesquisa: as fontes que tratam de letramento dão importância aos gêneros literários e conhecimentos linguísticos, em destaque a base fonêmica da língua portuguesa, mas as fontes que tratam de formação de professores permanecem com ênfase em outros temas. Logo, são necessárias pesquisas de campo na realidade escolar, da prática à teoria e da teoria à prática, que promovam novas aproximações e reflexões a respeito dos conhecimentos elencados no trabalho, a fim de mitigar problemas estruturais na alfabetização.
\end{abstract}

Palavras-chave: Linguística. Literatura. Letramento. Alfabetização. Formação de professores.

\section{Linguistics and Literature Topics in Literacy and in Teachers Education Literacy}

\begin{abstract}
This article is entitled "Topics of Linguistics and Literature in Literacy and literacy "and comes to knowledge of Linguistics and Literature in need of reinterpretation in Initial and continuing academic formation of literacy teachers. The purpose of this paper is not to Respect of theories and currents of Linguistics about the initial literacy or discourse on phonology of the language Portuguese, nor to argue about Theory, Critique or History of Literature, but is to provoke reflection and discussion on topics of the theoretical framework of Linguistics and Literature absent or poorly understood inTraining of literacy teachers and teachers of Portuguese Language. Within this proposal, it is imperative that make brief remarks also about paradigmatic changes on teacher training and implication of the issues analyzed in the school career of students. Under the method of bibliographical research, With cross-referencing of sources from the last ten years and others older, and interpretation of content, the arguments Have been built in order to return to the importance of the theme in parallel with other Academic discourses. Araújo and Oliveira (2008) and Pimenta (1996), among others, form the references of Theoretical basis and contribute to the result of the research: the sources that deal with literacy give Importance to liter ary genres and linguistic knowledge, highlighting the phonemic basis of the languagePortuguese, but the sources that deal with teacher training remain with emphasis on other themes. Therefore, Field research is needed, from practice to theory and from theory to practice, to promote New approaches and reflections on the knowledge listed in the work, in order to mitigate problems Structural changes in literacy.
\end{abstract}

Keywords: Linguistics. Reading. Literature. Literacy. Teacher training

\footnotetext{
${ }^{1}$ Professor de Língua Portuguesa da rede pública de ensino do Estado do Ceará, especialista em Psicopedagogia Clínica e Institucional, músico e mestrando em Educação pela Anne Sullivan University. E-mail: prof_eliabe@yahoo.com.br;
} 
Id on Line Revista Multidisciplinar e de Psicologia

Id on Line Multidisciplinary and Psycology Journal

\section{Introdução}

A realidade da nova ordenação das relações internacionais e transnacionais mostra mudanças econômicas, sociais e culturais de grande envergadura que configuram na educação escolar o novo perfil de estudante e de aluno, bem como novos paradigmas de gestão do conhecimento. A intensidade das trocas culturais não tem precedentes antes de 1970, quando começou a acontecer a globalização dos sistemas de produção e das transferências financeiras, o fluxo de informação em escala mundial e o deslocamento de massa de pessoas.

Dentro do recorte temporal de quatro décadas atrás aos dias atuais, acontece o processo de reconstrução da identidade do professor e a atualização das demandas curriculares no processo de formação acadêmica inicial e contínua dos docentes. Emergem da nova dinâmica social paradigmas de gestão do conhecimento que põem ainda mais em evidência o zelo e o profissionalismo na educação escolar fundamental.

Para Lévy (1999, p. 173), a dinâmica social do conhecimento na contemporaneidade impõe novas experiências de savoir-faire, ou seja, saberes e competências úteis os quais eram perenes na escala da vida humana de gerações anteriores. Em outras palavras, para as gerações de quarenta anos atrás a maioria dos saberes e das competências adquiridas na formação acadêmica seriam úteis a vida inteira, mas para a geração de hoje ficam obsoletos mesmo antes de se concluir a carreira ou o percurso profissional. Assim, ressignificar e atualizar são os verbos da ordem do dia.

Torna-se imperativo repensar as práticas de letramento durante todo o percurso escolar que implica participação cidadã fora da escola. A atenção maior deve estar na base desse percurso, visto que efeitos positivos ou negativos surtirão para formar ou não "cidadãosprofissionais" críticos e autônomos no que diz respeito à gestão do seu conhecimento e à participação nessa nova "economia do conhecimento coletivo".

Dúvidas e mistificações ainda persistem no inconsciente coletivo a respeito das pedagogias ditas tradicionais e de novas práticas de ensino chamadas de pedagogias experimentais. Reconhecendo que no meio da realidade escolar brasileira, pública e privada, predominam práticas e rotinas tradicionais, não se pode negar que o despertar crítico da nova 
Id on Line Revista Multidisciplinar e de Psicologia

Id on Line Multidisciplinary and Psycology Journal

geração de professores está acontecendo e que isso põe em andamento novas experiências pedagógicas.

A expressão "pedagogias tradicionais" é usada, para a finalidade deste artigo, em seu sentido abrangente, resumindo as concepções e práticas pedagógicas que tendem à homogeneização metodológica, isto é, não consideram as especificidades, singularidades ou idiossincrasias dos sujeitos no processo de ensino-aprendizagem, uma vez que as políticas e os sistemas de ensino onde predominam essas pedagogias também são geridos para a perpetuação desse modelo, à propósito da desatualização do conceito de "escola de massa", tema pertinente a outras pesquisas.

No grupo das pedagogias experimentais estão propostas metodológicas que trabalham para identificar e desenvolver potencialidades singulares dos sujeitos através de técnicas, recursos, abordagens e sequências didáticas diferentes das tradicionalmente encontradas na maioria das escolas públicas e privadas. Salienta-se que essas novas experiências ainda são a minoria, mas aumentam lentamente de número e se destacam na qualidade da aprendizagem que promovem.

Contudo, mesmo sob prismas diferentes a respeito do letramento, pedagogias tradicionais e experimentais devem cumprir com êxito a fase específica que incide sobre o desenvolvimento inicial de competências de leitura e escrita: a alfabetização.

Nesse processo dialético de coexistência de velhos e novos paradigmas de educação escolar, ora em conflito ora em complementaridade, destaca-se, no âmbito da trajetória acadêmica inicial e contínua, a formação dos pedagogos alfabetizadores e dos professores de Língua Portuguesa das séries finais do Ensino Fundamental.

Há diversos questionamentos de pesquisadores sobre o motivo pelo qual conhecimentos recentes da Pedagogia e das ciências aplicadas à educação não são usados a contento no letramento infantil. Isso traz o foco da discussão mais uma vez para a necessidade de mudança no processo de formação de professores.

No entanto, quando o macrotema é "Educação", predominam nos discursos acadêmicos, nos campos, nas linhas de pesquisa e nos cursos de formação continuada temas relacionados à Didática, à História da Educação e à Psicologia. A predominância parece óbvia. Tendo sua importância inteiramente justificada ao longo do século XX, esses temas e áreas do 
Id on Line Revista Multidisciplinar e de Psicologia

Id on Line Multidisciplinary and Psycology Journal

conhecimento precisam, ademais, ser acompanhados por outros, os quais costumam ter mais respaldo apenas dentro das ciências nas quais se originaram.

Por isso, o presente artigo tem por intuito chamar a atenção de professores atuantes nas fases de pré-alfabetização e alfabetização a respeito da imprescindibilidade de conhecimentos técnicos e científicos oriundos da Linguística e dos Estudos Literários. Esses conhecimentos precisam ser resgatados e ressignificados no planejamento educacional e na metodologia de ensino para que contribuam com resultados positivos e cooperem preventivamente contra problemas de aprendizagem resultantes de má alfabetização.

Para a consecução da discussão proposta, o trabalho está organizado em três pontos principais. O primeiro é o ponto de partida da problematização, no qual se justifica a necessidade de repensar a renovação curricular no Brasil e de resgatar tópicos técnicos e científicos pertinentes ao tema "formação de professores", especificamente alfabetizadores. O segundo ponto consiste no recorte de alguns conhecimentos linguísticos diretamente envolvidos na condução e mediação do processo de letramento inicial em língua materna neste caso, alfabetização em língua portuguesa. O terceiro ponto traz considerações acerca da Teoria Literária e as implicações da literatura no processo de letramento. Por fim, apresentamse os resultados da pesquisa e a conclusão.

\section{Formação de professores na nova dinâmica do conhecimento}

Muitos problemas de qualidade do ensino perpassam a formação de professores, os quais são submetidos a programas curriculares em boa parte obsoletos. Em relação à formação de professores alfabetizadores, que atuam nas séries iniciais do ensino fundamental, verifica-se o desconhecimento de temas estruturais em sua atuação.

Sabe-se que a massificação da oferta através de programas e políticas públicas, tanto do ensino médio em processo de universalização, como do ensino superior, são conquistas históricas, em parte; por outro lado, são também estratégias políticas para perpetuação das relações de poder e mecanismos de adaptação aos imperativos econômicos e culturais da marcha histórica do capitalismo globalizante. 
Entretanto, a generalização da oferta não pode continuar servindo apenas de mecanismo para alimentar estatísticas e promover gestões partidárias, como acontece no Brasil. É necessário um ganho de qualidade para contrabalançar paradigmas quantitativos que imperam na interpretação das políticas públicas de educação.

Sobre a formação acadêmica inicial, o cenário universitário brasileiro ainda é fortemente caracterizado pelo currículo formal, na perspectiva burocrática e cartorial, isto é, com vistas à certificação. A burocracia, no sentido em que é entendida - como excesso de protocolos e rotinas consagradas pelo uso, e distantes dos significados originais que justificaram a sua criação no passado - é um problema relacionado à história das universidades no Brasil, tema este pertinente para outras pesquisas.

A certificação é outro problema relacionado: no século XIX, quando os sistemas educacionais se consolidaram, a avaliação como medição do conhecimento se institucionalizou progressivamente e cristalizou o paradigma da pedagogia do exame, articulada em função da certificação. Nela, há descuido notório dos problemas de formação, dos processos cognitivos e da aprendizagem, desde a base fundamental até o nível superior.

Além disso, ainda há barreiras que separam a escola da universidade e separam ambas da sociedade. São relações de poder sustentadas por paradigmas que perpetuam a escola como o espaço privilegiado e inconteste de divulgação do conhecimento historicamente construído, e a universidade como único espaço onde se fazer ciência.

A dinâmica do conhecimento na contemporaneidade prova, mediante tamanha articulação social via internet e Tecnologias da Informação e Comunicação, que escola e universidade já não detêm mais esses status. Agora, compartilham essas funções sociais com outras instâncias divulgadoras do saber - organizações, sindicatos, igrejas, associações e comunidades virtuais.

Existem cursos protocolados para certificação e cursos livres acessíveis a uma massa cada vez maior de professores, tanto em modalidade presencial como a distância, mas no que diz respeito à formação contínua como desdobramento e ressignificação de conhecimentos, são pouco eficientes para alterar a realidade de sala de aula e da escola por não colocarem a prática docente e pedagógica escolar nos seus contextos, como ponto de partida e de chegada da 
Id on Line Revista Multidisciplinar e de Psicologia

Id on Line Multidisciplinary and Psycology Journal

formação, acabando, pois, como tentativas inoperantes de atuar sobre a realidade escolar e seus problemas (FUSARI, 1988; PIMENTA, 1996).

Logo, são pertinentes pesquisas a respeito da ressignificação de saberes consagrados historicamente e a incorporação de outros necessários à docência como prática social complexa e multifacetada em decorrência da sociedade capitalista globalizada, cujas contradições aparecem na realidade escolar.

Não obstante, considera-se ainda mais importante a necessidade de resgatar conhecimentos especificamente implicantes na fase inicial do letramento com a língua materna, comumente chamada de alfabetização, cujos efeitos, como se sabe, se estendem à vida adulta. Esses conhecimentos estão esfacelados nas práticas alfabetizadoras e precisam obter novamente a sistematicidade. É a proposta que vem a seguir.

\section{Consciência fonológica, consciência fonêmica e decodificação}

Não há dúvida que o título acima encerra o recorte de um tema de estudo imprescindível para professores de língua portuguesa e pedagogos, pois aponta para a base do letramento inicial infantil e sua relação com o futuro aprendizado das regras ortográficas, no ensino da língua materna.

Vale ressaltar inicialmente que o português é uma língua com muitas variações de fonemas vocálicos. Logo, na fase de desenvolvimento da consciência fonêmica - aprendizado dos fonemas da língua - é sugestivo que o professor trabalhe de forma prática e lúdica mediante exercícios, atividades e dinâmicas sobre a diversidade da pronúncia de vogais, primeiramente com palavras da realidade biossocial do educando, depois com palavras diferentes para aumentar o vocabulário.

No tópico linguístico a respeito do estudo dos fonemas, lembra-se também que em sílaba tônica há sete vogais distintivas em língua portuguesa: /a/ aberto e fechado; /e/ aberto e fechado; /i/; /o/ aberto e fechado; e /u/. Essa quantidade se reduz de sete para cinco em posição prétônica, devido à tendência de neutralização entre as vogais médias anteriores - /e/ aberto e fechado - e as vogais médias posteriores $-/ \mathrm{o} /$ aberto e fechado ${ }^{1}$.

${ }^{1}$ A Tabela Fonética Internacional tem símbolos mais específicos, para quem se interessar. 
Disso decorre que a abertura ou fechamento de vogais nessas sílabas não implicam mudança de sentido e representam variações linguísticas. Casos assim acontecem em palavras como pescar e morar (observe-se o /e/ e o /o/ nas primeiras sílabas - pronúncia aberta na variação nordestina e fechada na pronúncia carioca). Essa ilustração demonstra para o alfabetizador o valor desse tópico de conhecimento e o seu aproveitamento na pré-alfabetização e na alfabetização.

Se até os sete anos de idade a criança adquire gradativamente o sistema fonológico, isto é, os fonemas próprios da comunidade linguística na qual está inserida (o que não necessariamente é o registro culto de prestígio na sociedade), então é nessa faixa etária que a educação fonológica e fonêmica deve ser mais cuidadosa e sistemática, incluindo o repertório de conhecimentos que adiante serão apresentados.

Em consonância com Araújo e Oliveira (2008), aqui se considera o continuum consciência fonológica, consciência fonêmica e decodificação, no aspecto cognitivo, o que não contraria o continuum de fala que a criança deve visualizar e aprender a analisar - palavras, sílabas, letras e fonemas.

Dentro da abordagem do primeiro continuum acima apresentado, consciência fonológica consiste na "capacidade de identificar e discriminar diferentes sons. Ela é fundamental para o desenvolvimento posterior da consciência fonêmica (identificar que as palavras têm sons) e da decodificação (identificar a correspondência entre os sons e as letras)." (ARAÚJO e OLIVEIRA, 2008, p. 65). Ele diz respeito à decodificação ou leitura decodificadora, enfatizando o aspecto da pronúncia.

Vê-se que a parte fundamental estimulante está na fase de consciência fonológica. Não obstante, ambiente familiar e ambiente escolar rico de estímulos, nesse caso principalmente auditivos, são condições favoráveis para o desenvolvimento da consciência fonêmica e da decodificação, além do aspecto preventivo no que diz respeito às dificuldades de leitura e escrita, descritas pela "literatura psicopedagógica" como dislexia, disgrafia e disortografia.

O segundo continuum, apresentado anteriormente, se aproxima da perspectiva de Frith (1985), o qual considera três estratégias básicas para manipular a palavra escrita, ou seja, com vistas à ortografia: a logográfica, a alfabética e a grafofonêmica. Elas implicam, 
Id on Line Revista Multidisciplinar e de Psicologia

Id on Line Multidisciplinary and Psycology Journal

respectivamente, o reconhecimento da imagem gráfica da palavra, a análise da palavra nos componente grafêmicos e fonêmicos, e a decodificação das relações grafofonêmicas.

Todavia, a ausência de ambiente propício não forma, segundo estudos mais aceitos de Psicolinguística e Psicopedagogia, o quadro etiológico de dislexia, disgrafia ou disortografia, porque o quadro disléxico se compõe de inúmeros fatores.

Como há crianças as quais vivem em ambientes estimulantes e ainda têm dificuldades de leitura e escrita, tais ambientes funcionam até mesmo para revelar mais facilmente para o psicopedagogo os sinais de um quadro disléxico, mediante o contraste agudo entre os estímulos e a persistência do problema. Isso não implica dizer que tal situação estimulante não possa vir a ser preventora e compensadora de problemas em fases posteriores do letramento.

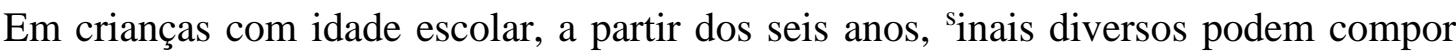
quadro disléxico: enorme lentidão ou muita rapidez ao fazer as tarefas e com muitas inadequações nas respostas; letra bonita e compreensão pobre; fluência inadequada; acréscimos, omissões ou distorções nas palavras lidas e escritas, inclusive borradas e ininteligíveis; só faz leitura silenciosa ou apenas em voz alta; transmite o que sabe apenas oralmente; tem imaginação criadora sempre ativa; é desatento ou atento a todos os estímulos do ambiente; possui autoimagem e autoestima baixas; perde-se facilmente no espaço e no tempo; esquece com frequência os pertences; tem bruscas mudanças de humor ${ }^{2}$.

Diante dessa problemática, as demandas para reformulações curriculares na formação acadêmica (inicial e contínua - PIMENTA, 1996) dos pedagogos e outras demandas para o planejamento pedagógico são mais rigorosas, dada a importância das habilidades fundamentais adquiridas pelo educando na primeira infância, mediadas por profissionais.

Araújo e Oliveira (2008, p. 97) ainda chama a atenção sobre cuidados do professor na fase de consciência fonêmica, na qual as regras são as da fonética e as atividades são orais, e, portanto, se descartam, pela irrelevância nesse momento, regras gramaticais de silabação e separação de sílabas. O autor enfatiza para ambas as fases, consciência fonológica e consciência fonêmica, atividades lúdicas envolvendo música com rimas, danças, brincadeiras e cantigas de roda, além da "contação" de histórias infantis dramatizadas e preenchidas por recursos de sonoplastia.

2 Esses sinais estão resumidos no site "ganhesempremais.com.br/psicopedagogia" 
Na verdade, os dois continuum correspondem a um único processo analítico da criança, o qual consiste na análise da fala, da leitura e da escrita. Essas etapas constituem a metacognição (habilidade de aprender a aprender), conceito estudado também na Psicolinguística e na Psicopedagogia. Reitera-se que falhas pedagógicas no processo podem resultar em dificuldades de aprendizagem de leitura e escrita estendidas até a vida adulta.

A respeito do estudo da trajetória das mudanças sonoras na língua portuguesa, várias correntes da Linguística se debruçaram e deixaram teorias ainda hoje influentes. É pertinente elencá-las a seguir, resumidamente, uma vez que esse conhecimento é de grande valia para o pedagogo e interfere no desenvolvimento da consciência fonêmica e na decodificação por parte do estudante.

No fim do século XVIII, a perspectiva neogramática trouxe em seu constructo teórico as leis fonéticas ${ }^{3}$. Apoiada no método histórico-comparativo, aproximava línguas com padrões fonológicos semelhantes ou analisava dois estágios históricos de uma mesma língua. Nessa perspectiva, predominava o teor determinista das leis fonéticas, e consequentemente o descarte de fatores gramaticas e semânticos nas possibilidades de mudanças sonoras no idioma. Sem o determinismo, as leis fonéticas ainda hoje figuram no conjunto de conhecimentos da fonologia do português.

Depois, no século XIX, a perspectiva dialetológica defendeu a influência das variantes linguísticas nas mudanças sonoras da língua, com ênfase na variação diatópica (variação linguística por região geográfica). Usando o método de análise da geografia linguística, criticou o absolutismo das leis fonéticas, sem, no entanto, descartá-las. Nesta perspectiva e na anterior, a mudança sonora sempre começa no nível do fone ou do fonema.

Já no difusionismo lexical, corrente posterior, o foco inicial da mudança sonora depende do caso. Assim, há a tendência de que a mudança comece no nível da palavra (unidade básica de análise nessa perspectiva) para depois atingir o fone ou o fonema. Em linhas gerais, quer dizer que, nessa corrente, diversas questões afetam antes a palavra, para depois afetar unidades sonoras menores como o fone ou o fonema. Há ambientes fonéticos propícios a alterações

\footnotetext{
${ }^{3}$ Lei do menor esforço, lei da persistência da consoante inicial e lei da persistência da tônica. Para melhores esclarecimentos, sugere-se consultar a "Gramática Histórica", de Ismael de Lima Coutinho (Rio de Janeiro: Livraria Acadêmica, 1967).
} 
Id on Line Revista Multidisciplinar e de Psicologia

Id on Line Multidisciplinary and Psycology Journal

sonoras na língua, mas também existem fatores lexicais, como frequência de uso e valorações sociais, além de questões semânticas, que interferem nas mudanças.

Palavras como "português", "bezerro", "teoria" - "purtuguês", "bizerro" e "tioria", mudanças vocálicas possíveis nas variações linguísticas - dentre outras, podem ter alterações sonoras na sílaba pré-tônica não apenas dentro da margem de possibilidades explicativas das leis fonéticas, ou na margem mais ampla das variações diatópicas, mas também por causa de questões sociais, pragmáticas, ideológicas e semânticas. É o que ramos da Linguística como a Psicolinguística, Linguística Cognitiva e Sociolinguística vêm investigando nas últimas décadas.

A sociolinguística sintetiza os conhecimentos acerca da trajetória das mudanças sonoras na língua e acerca também da identificação de constantes e padrões lógicos de ocorrência de fonemas e sua tonicidade em sílabas, o que permite melhor orientação ortográfica no idioma, para quem está em fase de letramento inicial, e ainda acrescenta outras visões e conhecimentos, além de conscientizar sobre a carga semântica e ideológica, e a valoração social das fugas desses padrões. Em suma, chama a atenção para as variações linguísticas e a pertinência do conceito de língua funcional ${ }^{4}$.

Recentemente, estudos linguísticos têm estendido o horizonte e a perspectiva para considerar outros fatores que também interferem no letramento, na fase pós-alfabetização e durante todas as fases escolares. Mediados pelas novas tecnologias de informação e comunicação, os processos sociais contemporâneos, transnacionais, nacionais e regionais, mormente oriundos do cosmopolitismo e da globalização, interferem no idioma e na comunicação verbal, provocando alterações no modo de pensar, raciocinar e se comunicar, ressignificando gêneros textuais orais e escritos já existentes e criando novos gêneros, em formato digital, por exemplo. E mais: esses processos reforçam teorias e estudos na Linguística contra o determinismo de correntes tradicionais como a perspectiva neogramática, apesar de sua importância.

\section{Letramento e literatura: perspectivas}

\footnotetext{
${ }^{4}$ Nesse conceito, grosso modo, as variações linguísticas podem ser diatópicas (geográficas), diafásicas (fase ou registro linguístico situacional) ou diastráticas (estrato, classe ou segmento social).
} 
Id on Line Revista Multidisciplinar e de Psicologia

Id on Line Multidisciplinary and Psycology Journal

O conceito de letramento adotado para o propósito deste artigo é o consenso provisório de várias perspectivas que aqui convergem, em forma de síntese: existência social e cultural manifestada na escrita, com diferentes sentidos e funções, e diferentes graus de participação ética e estética; incluem-se também nesse conceito padrões diferenciados de circulação e distribuição social da escrita, no cotidiano e no imaginário.

Chama-se a atenção, apoiado em Rangel (2005, p. 130), a respeito do retorno da leitura - especialmente literária - na perspectiva do letramento. Com isso, as idiossincrasias do sujeito, as particularidades das situações e a materialidade dos textos podem, por direito, ocupar o centro das atenções.

E para o propósito desse artigo, destaca-se o aspecto da materialidade dos textos literários no seu estrato sonoro (significante) percebido por crianças em fase de conscientização fonológica e fonêmica durante os momentos de escuta de histórias contadas pelos professores.

A ênfase na sonoridade verbal e não verbal previamente planejada pelo alfabetizador e aplicada na "contação" de histórias literárias, pode servir de rica fonte de estímulos na fase de consciência fonológica e depois corpus para reflexão linguística nas fases de consciência fonêmica e de decodificação, além de abrir caminho para formar o futuro sujeito para quem a leitura literária significará instigante experiência estética e cultural.

Marcuschi (1996) já salientou que os livros didáticos e sua forma de apresentação dos textos literários são corresponsáveis pelas deficiências e inadequações de leitura apontadas em avaliações oficiais como o SAEB (Sistema de Avaliação da Educação Básica) e o PISA (Programa Internacional de Avaliação de Estudantes).

Zilberman (2005) também salienta o aspecto metodológico, mas acrescenta que a fragmentação dos textos literários nos livros didáticos de português, em vez do acesso às obras literárias, também é componente forte para não formar leitores literários.

Porém, problemas de leitura incerta ou leitura rarefeita - literária e não literária - são efeitos do letramento inoperante nas fases iniciais da vida escolar. Isso quer dizer que a compreensão leitora do brasileiro é por vezes defasada, deficiente ou prejudicada - pelo menos no sentido de não legitimada socialmente - por objetivos de leitura mal definidos, pela falta de hábito e experiência de leitura para o proveito pessoal e técnicas de alfabetização homogeneizadoras que não tendem às idiossincrasias dos sujeitos. 
Devido à predominância da Psicologia como ciência aplicada à educação, a leitura literária tende a ser compreendida apenas como funcionamento ou desempenho proficiente de competências e habilidades adquiridas ao longo do processo de ensino-aprendizagem.

A singularidade dos sujeitos e das situações não ocupa o centro da cena e continuará sem ocupar se o modelo de escola homogeneizadora estiver mantido. A preparação cuidadosa de lugar, momento, tema do texto e técnicas de leitura literária que permitam ao estudante, principalmente iniciante, ter experiência marcante com a literatura, no aspecto da fruição estética e do bem estar, está à margem das sequências didáticas, as quais são presas ao livro didático quase sempre distante da realidade escolar.

É necessário que os profissionais escolares envolvidos na educação de crianças contribuam para criar condições a fim de aproximar referências culturais distintas - o escritor e o leitor/ouvinte - no momento da leitura dos alunos e no momento da escuta de "contação de histórias" pelo professor.

\section{Resultados da pesquisa}

É correto constatar, diante do exposto, que as fontes que tratam de letramento dão importância aos conhecimentos linguísticos e literários; destas, poucas dão destaque à base fonêmica do letramento inicial em língua portuguesa; elas dão mais ênfase aos gêneros textuais, atualmente um rico campo de pesquisas. Paralelamente, as fontes que tratam de formação de professores permanecem com ênfase em outros temas ligados à Didática, História da Educação e Psicologia.

Neste trabalho foram mencionadas as histórias infantis como elemento didático da "contação" de histórias - ou estórias para algumas teorias literárias - principalmente na manifestação do estrato sonoro da língua, a fim de estimular a atenção dos estudantes sobre os significantes e os significados, e assim estudar a materialidade fonêmica do idioma e do próprio texto literário.

Logo, considera-se pertinente a proposta apresentada neste artigo, uma vez que fez proposições e encaminhamentos científicos profícuos. Não sendo hermética, essa proposta está atrelada a outras pesquisas - de campo, na realidade escolar, da prática à teoria - que promovam 
novas aproximações e reflexões a respeito dos conhecimentos elencados no trabalho, a fim de mitigar problemas estruturais na alfabetização.

\section{Conclusão}

Em suma, a argumentação proposta anteriormente aponta a síntese reflexiva a respeito da postura do professor, em destaque o alfabetizador responsável pela base de leitura e escrita cujos desdobramentos têm repercussões durante todo o processo de letramento, o qual se estende até o ensino médio e até mesmo o superior, mormente no uso da língua materna para expressão, criticidade e participação social.

Pesquisadores propõem que desenvolver habilidades de pesquisa da teoria e da prática (DEMO, 1990; grifos meus), repetir processos de reflexão sobre a própria prática (SCHÖN, 1990) e articular-se com a dinâmica social do conhecimento são saberes imprescindíveis para o professor se situar no seu novo perfil de mediador e gestor do conhecimento na sociedade contemporânea.

Não sendo redentora da sociedade - como outrora se defendia nas teorias não-críticas da educação, em estudo de Saviani (2007) -, nem unicamente reprodutora das desigualdades sociais, a educação escolar deve assumir a característica de uma atividade social articuladora de conhecimentos os quais devem passar pela reflexão e se transformar em sabedoria para a humanização (MORIN, 2003).

Em outras palavras, apenas adquirindo consciência e reflexão é possível não permitir que o conhecimento continue sendo mais uma via de sustentação de poder, mas um caminho para a humanização. Retirar o sujeito aprendente da condição de analfabeto e colocá-lo na condição de analfabeto funcional não é apenas insuficiente, mas é desumano porque contribui para a perpetuação do controle ideológico das classes dominantes.

\section{Referências}

ARAÚJO E OLIVEIRA, João Batista. ABC do Alfabetizador. Instituto Alfa e Beto: Brasília, 2008. 
Id on Line Revista Multidisciplinar e de Psicologia

Id on Line Multidisciplinary and Psycology Journal

DEMO, Pedro. Pesquisa: princípio científico e educativo. São Paulo: Cortez, 1990.

FUSARI, José C. A educação do educador em serviço: treinamento de professores em questão. São Paulo, 1988. 250p. Dissertação (mestrado) - Pontifícia Universidade Católica de São Paulo.

LÉVY, Pierre. Cibercultura. São Paulo: Editora 34, 1999.

MARCUSCHI, Luiz Antônio. Exercícios de compreensão ou copiação, nos manuais de ensino de línguas? [s.1.], [s.ed.], 1996. (Mimeogr.).

MORIN, Edgar. A cabeça bem feita: repensar a reforma, reformar o pensamento. Rio de Janeiro: Bertrand Brasil, 2003.

PIMENTA, Selma Garrido. Formação de professores - saberes da docência e identidade do professor. Revista da Faculdade de Educação da Universidade de São Paulo, v.22, n.2, p. 7289, jul. / dez. 1996.

RANGEL, Egon de Oliveira. Letramento literário e livro didático de Língua Portuguesa: “os amores difíceis". In Literatura e letramento: espaços, suportes e interfaces - o jogo do livro. Belo Horizonte: Autêntica/CEALE/FaE/UFMG, 2005.

SAVIANI, Dermeval. História das ideias pedagógicas no Brasil. Campinas: Autores Associados, 2007. 473p.

SHÖN, Donald. Educating the reflective practitioner. San Francisco: Jossey-Bass, 1990.

ZILBERMAN, Regina. Letramento literário: não ao texto, sim ao livro. In Literatura e letramento: espaços, suportes e interfaces - o jogo do livro. Belo Horizonte:

Autêntica/CEALE/FaE/UFMG, 2005.

Como citar este artigo (Formato ABNT):

SILVA, E.B.O. Gestão por Perversão: Tópicos de Linguística e Literatura no Letramento e na Formação de Alfabetizadores. Id on Line Revista Multidisciplinar e de Psicologia, Nov-Dez. de 2016, vol.10, n.32, p. 214-227. ISSN: 19811179.

Recebido: 30/10/2016

Aceito: $11 / 11 / 2016$ 